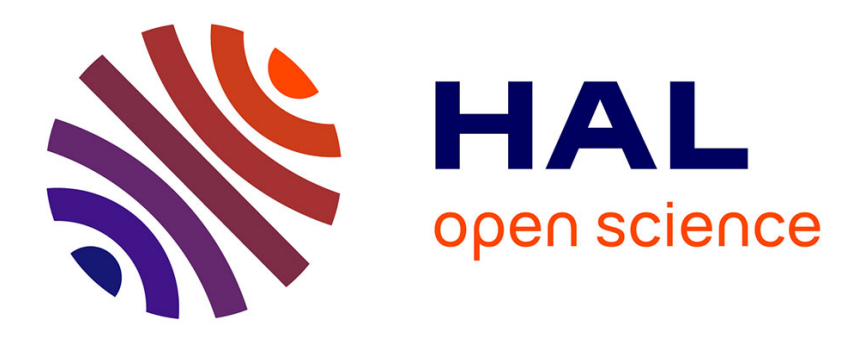

\title{
The thermal conductivity of amorphous Ce1-xAl x alloys between 1.5 and $350 \mathrm{~K}$
}

\author{
A. Guessous, J. Mazuer
}

\section{To cite this version:}

A. Guessous, J. Mazuer. The thermal conductivity of amorphous Ce1-xAl x alloys between 1.5 and 350 K. Journal de Physique Lettres, 1982, 43 (22), pp.801-807. 10.1051/jphyslet:019820043022080100 . jpa-00232128

\section{HAL Id: jpa-00232128 https://hal.science/jpa-00232128}

Submitted on 1 Jan 1982

HAL is a multi-disciplinary open access archive for the deposit and dissemination of scientific research documents, whether they are published or not. The documents may come from teaching and research institutions in France or abroad, or from public or private research centers.
L'archive ouverte pluridisciplinaire HAL, est destinée au dépôt et à la diffusion de documents scientifiques de niveau recherche, publiés ou non, émanant des établissements d'enseignement et de recherche français ou étrangers, des laboratoires publics ou privés. 
Classification

Physics Abstracts

$66.90-72.15 \mathrm{C}$

\title{
The thermal conductivity of amorphous $\mathrm{Ce}_{1-x} \mathbf{A l}_{x}$ alloys between 1.5 and $350 \mathrm{~K}$
}

\author{
A. Guessous and J. Mazuer (*) \\ Centre de Recherches sur les Très Basses Températures $\left({ }^{* *}\right)$, \\ C.N.R.S., B.P. 166 X, 38042 Grenoble Cedex, France
}

(Reçu le 26 juillet 1982, révisé le 10 septembre, accepté le ler octobre 1982)

\begin{abstract}
Résumé. - Nous avons mesuré la variation avec la température de la conductivité thermique d'alliages amorphes de CeAl. Pour 5 alliages dont la teneur en aluminium varie de 12 at. $\%$ à 86 at. \%, nous n'avons pas observé vers $5-10 \mathrm{~K}$ le plateau qui apparaît généralement dans la conductivité de réseau des systèmes amorphes. Nous montrons que la diffusion des phonons par les électrons ne permet pas d'expliquer cette absence de plateau.

Abstract. - We have measured the thermal conductivity of amorphous CeAl alloys as a function of temperature. For five alloys with an aluminium concentration increasing from 12 at. $\%$ to 86 at. $\%$, we did not observe the plateau which generally appears around $5-10 \mathrm{~K}$ in the lattice conductivity of amorphous materials. We show that phonon scattering from electrons cannot explain the absence of the plateau.
\end{abstract}

1. Introduction. - Thermal conductivity measurements on metallic glasses are generally performed in the low temperature region, between $0.1 \mathrm{~K}$ and $10 \mathrm{~K}$ [1-4]. When the electronic contribution is subtracted, the remaining phonon conductivity exhibits a $T^{m}$ variation $(m \sim 2)$ below $1 \mathrm{~K}$, a feature which is also observed in amorphous dielectrics and is well accounted for by the tunnelling state model $[5,6]$, although the actual nature of the low energy excitations involved in this model is not yet clarified. At higher temperatures, some discrepancies appeared between the phonon conductivities $k_{\mathrm{ph}}(T)$ of dielectric and metallic glasses, though the first published results on an amorphous PdSi alloy [7] exhibited the same temperature behaviour in the explored temperature range $(<100 \mathrm{~K})$ as observed for amorphous dielectrics, i.e. an almost constant phonon conductivity around $10 \mathrm{~K}$. But further experiments [8] on other glassy metals showed that this so-called " plateau » region does not always occur.

Due to some experimental difficulties that we will discuss later few results are available up to $100 \mathrm{~K}$ [8] and still less up to room temperature where, to our knowledge, only two measurements at $300 \mathrm{~K}$ have been published $[9,10]$. To try to get further information on phonons in glassy metals, and more particularly to look for the occurrence of the plateau, we studied a whole binary alloy family with variable composition rather than alloys of various materials. We chose the $\mathrm{Ce}_{1-x} \mathrm{Al}_{x}$ system which could be prepared in our laboratory and for which we also measured

(*) J. M. is also with Laboratoire d'Electrotechnique ERA 534, C.N.R.S.

(**) Associated to Université Scientifique et Médicale de Grenoble. 
the electrical resistivity and thermopower [11]. The plateau was never observed although $x$ was varied from 12 at. \% to 86 at. \%. Using a reactive sputtering technique, the samples were deposited on a low temperature substrate and then removed. Their typical thickness was $\sim 80 \mu \mathrm{m}$ and they were cut in rectangular form $\sim 20 \times 5 \mathrm{~mm}^{2}$. X-ray analysis provided proof of the amorphous structure. Aluminium concentration was determined by atomic absorption spectroscopy. The samples were not expected to be without impurities and the presence of around 1 at. $\% \mathrm{Ar}$ and 1 at. $\% \mathrm{H}_{2}$ was revealed by mass spectroscopy analysis performed on one of our samples so that the actual Ce concentration was about $2 \%$ less than $(1-x)$.

2. Experiments. - The experimental set up has been described elsewhere [12]. We used a fast cooling cryostat the principal feature of which is an evacuated calorimeter containing a cold source. The temperature of this source can be maintained successively at 1, 4.2 and $77 \mathrm{~K}$. After cooling, the sample is progressively heated from 1.5 to $350 \mathrm{~K}$. A small heater applies a temperature gradient $\Delta T$ along the specimen. $\Delta T$ is measured through an arrangement of two calibrated AuFechromel thermocouples. The thermal conductance $K$ of the sample is calculated from Fourier's law $P=K . \Delta T$ where $P$ is the electric power supplied to the heater. When calculating the measured thermal conductivity $k_{\text {meas }}$ we need to apply to $K$ a geometrical factor which introduces a systematic experimental error below $100 \mathrm{~K}$. In this low temperature range, the error on the absolute value of the thermal conductivity is not expected to be less than $15 \%$, but the variations of $k_{\text {meas }}$ with $T$ are known with a much greater accuracy which we estimate to be $\sim 1 \%$. When the temperature increases a parasitic conduction takes place due to radiation. This is a wellknown problem in thermal conductivity measurements : the emitted power from external surfaces must be minimized. This is generally obtained by using samples in the form of disks rather than wires or foils. For amorphous materials, which up to now can only be prepared in the form of thin foils such a solution cannot be used, so that the radiated power from the two surfaces of the sample may be much greater than the power transmitted by conduction along the sample. Furthermore this situation is accentuated by the generally low values of the thermal conductivity observed in disordered materials.

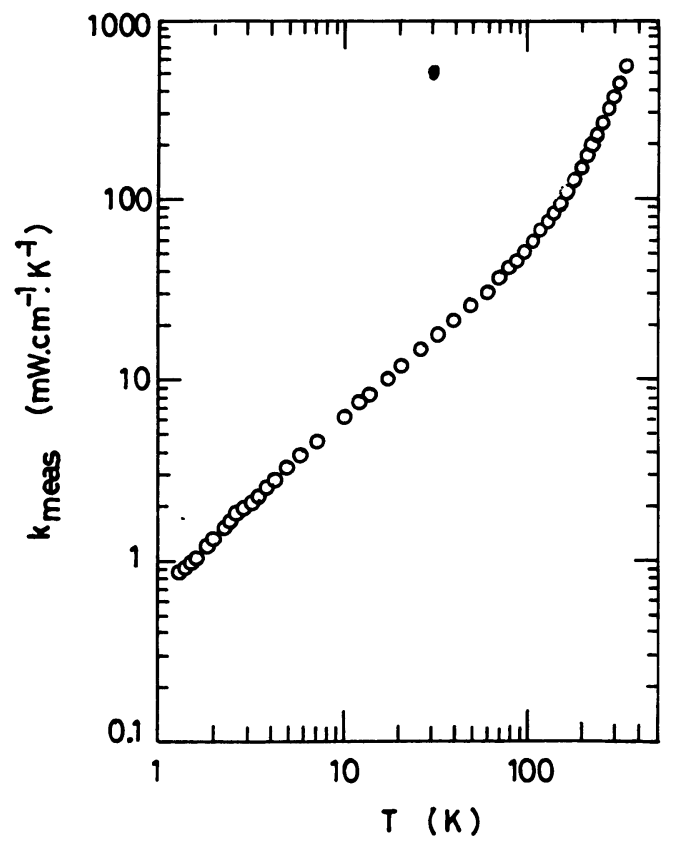

Fig. 1. - The apparent thermal conductivity as deduced directly from the experiment on a $\mathrm{Ce}_{14} \mathrm{Al}_{86} \mathrm{sample}_{\text {. }}$ 
It might be possible to reduce this radiated power with screens facing the sample and exhibiting the same temperature gradient. We considered this procedure to be too sophisticated experimentally. So we used a very simple graphical method which unfortunately leads to only very rough values of the thermal conductivity between 100 and $350 \mathrm{~K}$. The variations with $T$ of the conductivity calculated directly from experiments are shown on figure 1 . All the samples exhibit the same behaviour, more particularly a dramatic increase of $\boldsymbol{k}_{\text {meas }}$ in the high temperature range. We attributed this increase to the parasitic radiative transfer resulting from the small temperature difference between the sample and its environment. As a result of the differential form of Stephan's law this transfer is a cubic function of temperature. An extra $T^{3}$ term negligible at low temperature has then to be added to the thermal conductivity $k$ of the sample, so that, at high temperatures

$$
k_{\text {meas }}=k_{\mathrm{e}}+k_{\mathrm{ph}}+A T^{3}
$$

$k_{\mathrm{e}}$ and $k_{\mathrm{ph}}$ are the contributions of electrons and phonons respectively. $A$ is a coefficient which takes account of the temperature gradient, area and emissivities of the surfaces. An experimental proof of this cubic contribution was obtained previously when measuring a pure lead sample [12]. The problem is to estimate $A$ for each experiment; our evaluation is supported by two hypotheses which we discuss below.

1) The electron contribution to the thermal conductivity may be calculated by the WiedemannFranz law for metals. In alloys at intermediate temperatures deviations from this law are essentially encountered when the scattering process is mainly due to phonons [13]. Such a scattering may be more efficient in producing a thermal resistivity than an electrical one, i.e. the mean free path of electrons is not the same for electricity and heat transfers. In our samples, the residual resistivities are high, between 100 and $300 \mu \Omega$.cm, and their variations with $T$ are very smooth,

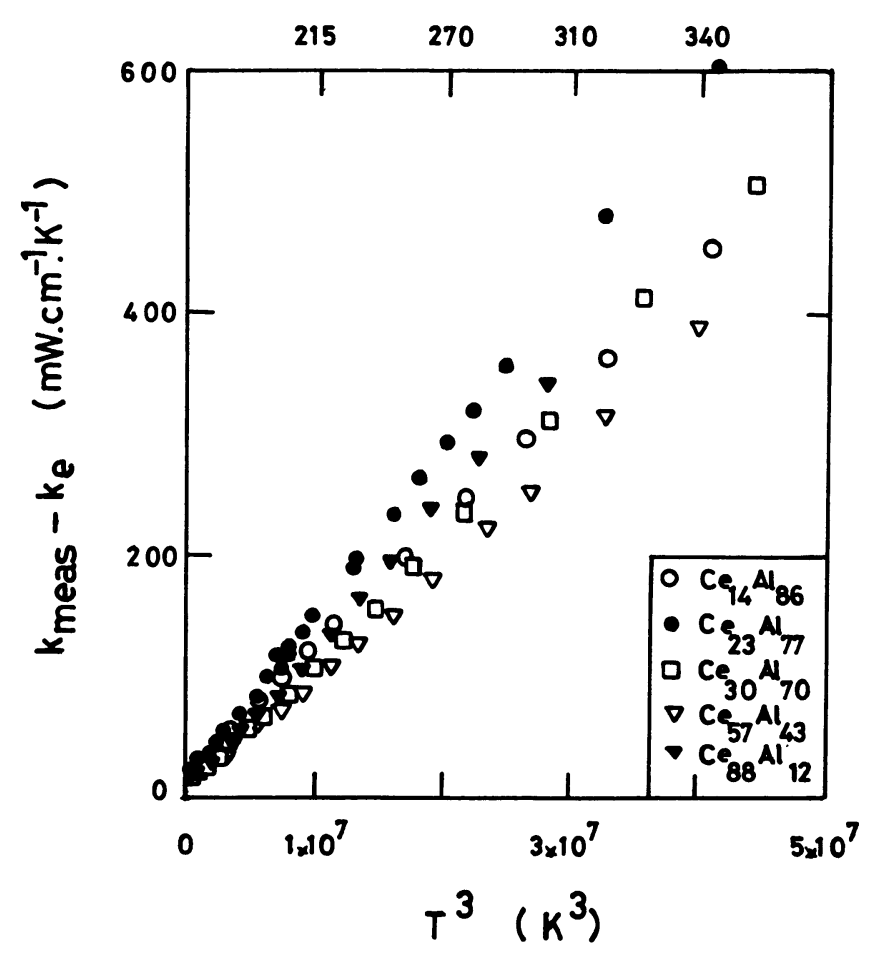

Fig. 2. - The difference between the apparent conductivity $k_{\text {meas }}$ and electronic conductivity $k_{\mathrm{e}}$ plotted as a function $T^{3}$. The upper scale shows the corresponding values of $T$ as a guide. 
less than $10 \%$ between 1.5 and $350 \mathrm{~K}$, two properties which are characteristic of intrinsic scattering by disordered ions and not phonon scattering. So we do not expect the Lorenz number $L$ to differ by more than several percent from its ideal value $L_{0}=2.45 \times 10^{-8} \mathrm{~W} . \Omega . \mathrm{K}^{-2}$. A qualitative test of the validity of the Wiedemann-Franz law was given [8] for an amorphous TiBe alloy by comparing the phonon thermal conductivity in the normal and superconducting states. Under this first hypothesis we therefore can calculate $k_{\mathrm{e}}=\rho^{-1}(T) L_{0} T$.

2) The phonon conductivity has been recognized to be generally very low $\sim 10 \mathrm{~mW} \cdot \mathrm{cm}^{-1} \cdot \mathrm{K}^{-1}$ near room temperature, with a weak positive slope in this range [14], which we assume to be the case for our CeAl alloys.

On figure 2, we have plotted $k_{\text {meas }}-k_{\mathrm{e}}$ as a function of $T^{3}$, for $100 \mathrm{~K}<T<350 \mathrm{~K}$. The curves are almost linear for all samples, which is a qualitative illustration of our hypothesis. Their slope $A$ allows us to calculate the parasitic radiative transfer. Deviations from linearity in some cases in the high temperature region may be due to a possible variation of the emissivities with temperature. The extrapolated ordinate at $T=0$, of order $10 \mathrm{~mW} \cdot \mathrm{cm}^{-1} \cdot \mathrm{K}^{-1}$ represents $k_{\mathrm{ph}}$ at $T \sim 300 \mathrm{~K}$, but obviously is given with very low accuracy if we recall that the equivalent conductivity of radiative transfer at $300 \mathrm{~K}$ is around $500 \mathrm{~mW} \cdot \mathrm{cm}^{-1} \cdot \mathrm{K}^{-1}$. This low value of $k_{\mathrm{ph}}$ at room temperature can be considered more correct than that deduced from a preliminary experiment on a $\mathrm{Ce}_{0.3} \mathrm{Al}_{0.7}$ alloy [12] for which the radiative term was estimated by comparison with experiments on a piece of pure lead having the same geometry.

3. Results and discussion. - With the above values of $A$, corrected if necessary to take account of the variation of the emissivities, we have drawn on figure 3 the variations of the thermal conductivity of our five samples. Using the Wiedemann-Franz law, we subtracted the electronic contribution to get the phonon contribution (Fig. 4). Except for the two samples which are very rich or very poor in $\mathrm{Al}$, the electron contribution is always less than $50 \%$ of that of the phonons in the low temperature range, and the electrons begin to dominate at $T \gtrsim 100 \mathrm{~K}$. For the two extreme specimens, $k_{\mathrm{e}}$ and $k_{\mathrm{ph}}$ are of same order up to $30-40 \mathrm{~K}$. For all samples at room temperature heat

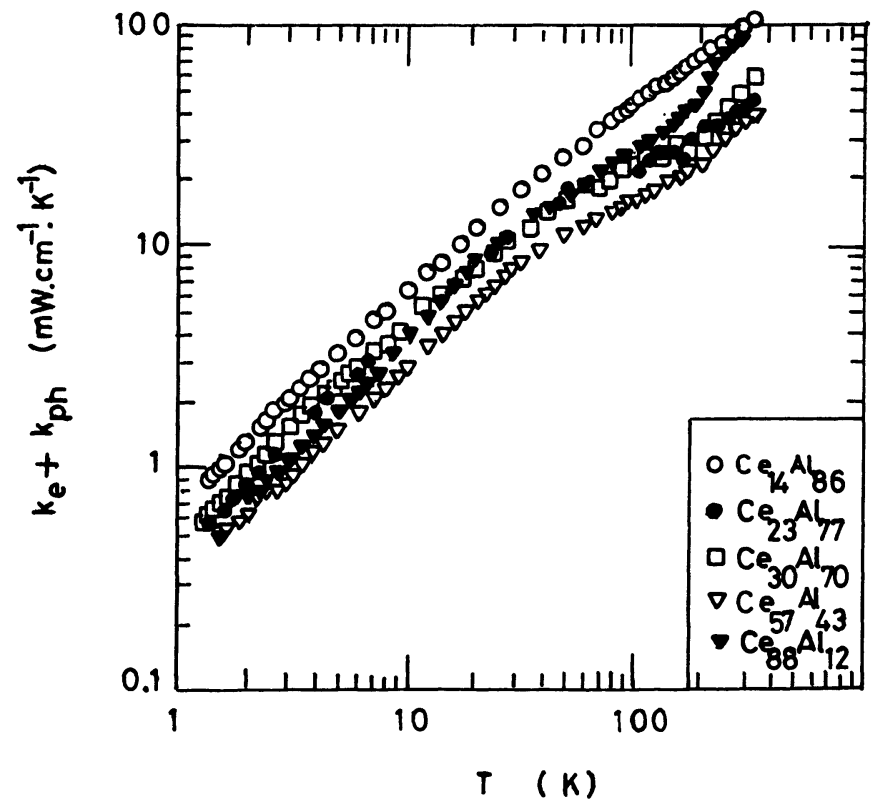

Fig. 3. - The variations with the temperature of the total thermal conductivity of the five amorphous CeAl alloys. 


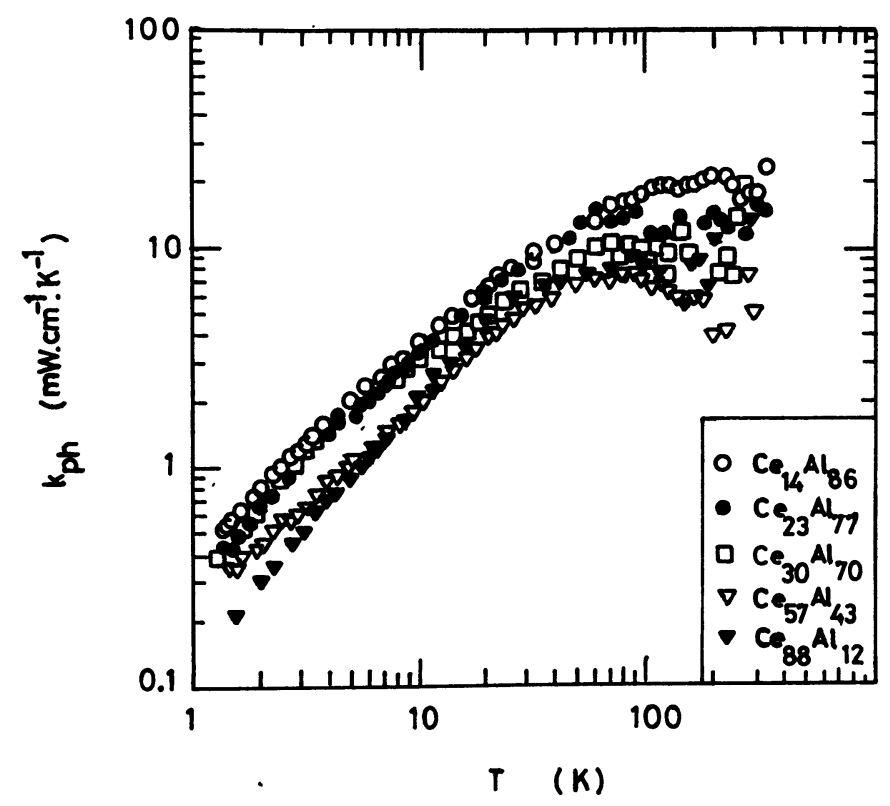

Fig. 4. - The variations with temperature of the phonon conductivity deduced from figure 3 by subtracting the electronic thermal conductivity.

is essentially transported by electrons. In the whole temperature range, the amplitude of $k_{\mathrm{ph}}$ is comparable with that of other amorphous materials $[8,14]$. Below $50 \mathrm{~K}$, the geometrical factor gives an absolute accuracy of $\sim 15 \%$ in $k_{\mathrm{ph}}$. But from $100 \mathrm{~K}$ to $350 \mathrm{~K}$, the accuracy is decreasing and the values are only rough indications as evidenced by the dispersion of experimental points on figure 4.

The most characteristic feature lies in the absence of the plateau previously observed in three glassy metals FeP, FeNi and TiBe [8]. For two other glassy metals PdSi and NiP, the plateau was present [8]. We do not wish to discuss here the microscopic origin of this plateau, a problem which is not yet clarified [15], but rather to see if this plateau is a universal property of dielectric and metallic glasses $[16,17]$.

If so, this would mean that when not experimentally observed in amorphous metals, the plateau would be masked by some other mechanism. As the essential difference between dielectric and metallic glasses is the density of free electrons, it has been argued that electrons might act as scattering centres for the phonons [4]. The phonon thermal conductivity would then be contributed by two terms obeying the Matthiessen rule for phonons :

$$
k_{\mathrm{ph}}^{-1}=k_{\mathrm{ph}-\mathrm{i}}^{-1}+k_{\mathrm{ph}-\mathrm{e}}^{-1} \text {. }
$$

The first term is associated with intrinsic structural scattering. $k_{\mathrm{ph}-\mathrm{e}}$ would be the phonon conductivity due to electronic scattering only. Evidence for such scattering was recently given for superconducting amorphous $\mathrm{Zr}$ based alloys $[4,18]$ for which the experimental values of $k_{\mathrm{ph}-\mathrm{e}}$ were shown to vary almost linearly with $T$. For $\mathrm{Zr}_{60} \mathrm{Be}_{40}$ alloys [4] the results are in good agreement with a simple free electron model. On the contrary, for a $\mathrm{Zr}_{70} \mathrm{Cu}_{30}$ alloy, although $k_{\mathrm{ph}-\mathrm{e}}(T)$ was linear in $T$ the results do not quantitatively agree with the values calculated from the free electron model [18] which gives at low temperatures :

$$
k_{\mathrm{ph}-\mathrm{e}}=1.82 \times \rho_{0} \theta_{\mathrm{D}} A n_{0}^{-2 / 3} T
$$


where

$k_{\mathrm{ph}-\mathrm{e}}$ is in $\mathrm{mW} \cdot \mathrm{cm}^{-1} \cdot \mathrm{K}^{-1}$,

$\rho_{0}$ is the residual resistivity in $\Omega$.cm,

$A$ the average mass number,

$\theta_{\mathrm{D}}$ the Debye temperature,

$n_{0}$ the average number of free electrons.

To determine qualitatively the variation of $k_{\mathrm{ph}-\mathrm{e}}$ with the aluminium concentration $x$ in our samples, we also applied the free electron model, with $n_{0} \sim(1-x+3 x)$. $\theta_{\mathrm{D}}$ is estimated for each alloy by comparison with the values for crystalline compounds deduced from heat capacity measurements [19] and listed with $\rho_{0}$ in the inset of figure 5. The variations of the phonon conductivity $k_{\mathrm{ph}}$ at $T=10 \mathrm{~K}$ are drawn as a function of the corresponding values of $k_{\mathrm{ph}-\mathrm{e}}$. These last values are very high, about one order of magnitude greater than $k_{\mathrm{ph}}$, a result which was previously obtained on $\mathrm{Zr}_{70} \mathrm{Cu}_{30}$ [18] for which the experimental and theoretical values differed by a factor 7 . Therefore the actual values of $k_{\mathrm{ph}-\mathrm{e}}$ for $\mathrm{CeAl}$ are probably lower. Nevertheless when considering the evolution of $k_{\mathrm{ph}}$ with $k_{\mathrm{ph}-\mathrm{e}}$ (Fig. 5) we see that the total phonon conductivity $k_{\mathrm{ph}}$ decreases as $k_{\mathrm{ph}-\mathrm{e}}$ increases, showing that the scattering from electrons is probably not a dominant process [20]. It seems then unlikely that in these $\mathrm{CeAl}$ alloys scattering of phonons by electrons could hide a possible plateau in $k_{\mathrm{ph}-\mathrm{i}}$. Further support for this argument can be found in an analysis of the experimental variations of $k_{\mathrm{ph}}$ with $T$ (Fig. 4) which are well fitted by a power law $\sim T^{m}$ with $0.9 \leqslant m \leqslant 1.15$ in the temperature range of interest. We have seen that $k_{\mathrm{ple}-\mathrm{e}}$ is also fitted by a power law with $m \sim 1$ [4]. A combination of these two laws through Matthiessen's rule to produce a plateau necessarily leads to unrealistic values of $k_{\mathrm{ph}-\mathrm{i}}$. These values are an order of magnitude greater than those generally observed in disordered alloys, and attributed to a dramatic fall of the phonon mean free path [21] for frequencies $\omega>\omega_{0} \sim 10 \mathrm{~K}$ (in thermal units).

Another way of discussing the absence of the plateau is to consider $\omega_{0}$ as a cut-off frequency which divides the phonon spectrum into two independent contributions [22]. Such a model was first proposed to explain the variations with the temperature of the thermal conductivity of

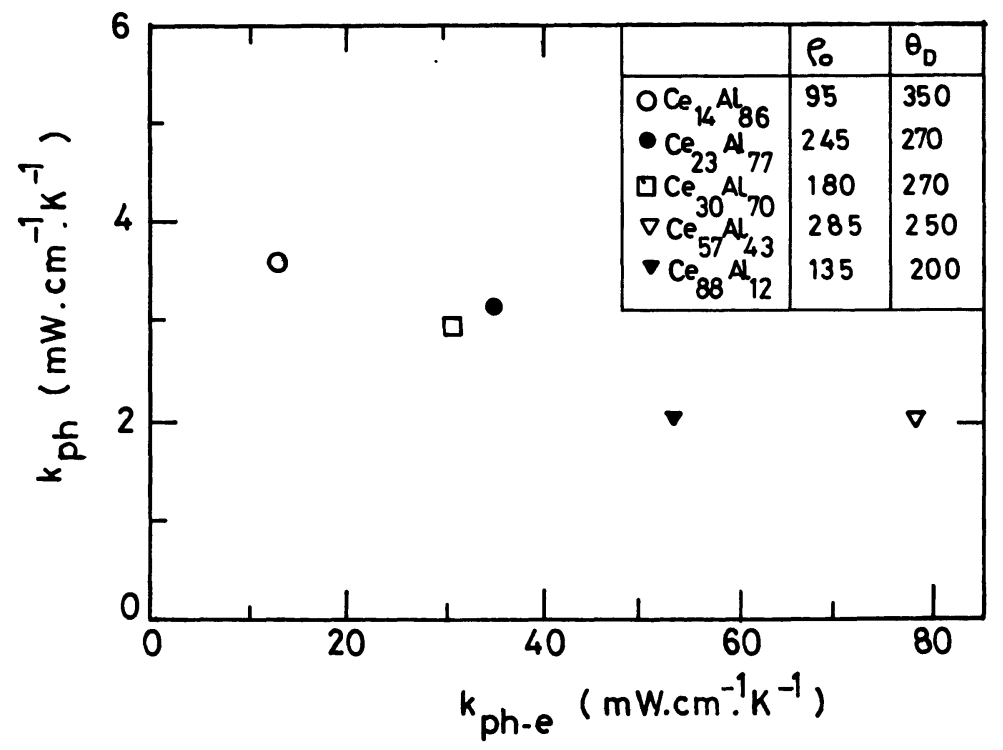

Fig. 5. - The variation of the experimental phonon conductivity as a function of the theoretical phonon conductivity due to phonon-electron scattering for the five $\mathrm{CeAl}$ alloys at $10 \mathrm{~K}$. The inset gives the values of the residual resistivities (in $\mu \Omega . \mathrm{cm}$ ) and Debye temperatures (in $\mathrm{K}$ ) for the five samples. 
quartz glass [23]. In this model, the low frequency phonons only contribute to the low temperature conductivity $L$ and the high frequency phonons only to the high temperature conductivity $\boldsymbol{H}$. The higher the ratio $L / H$ the wider would be the plateau [8]. Such considerations could explain why a slight bend appears in $k_{\mathrm{ph}}(T)$ at around $5 \mathrm{~K}$ for those three samples which exhibit the high phonon conductivity at $\sim 1.5 \mathrm{~K}$ (Fig. 4).

To conclude, it has been shown that for amorphous CeAl alloys, the low temperature thermal conductivity of the phonons is of the same order as that observed in other disordered alloys, but contrary to most measurements on glasses a plateau does not appear near $10 \mathrm{~K}$. Scattering of phonons from electrons does not seem to explain this behaviour. We cannot give a theoretical interpretation of our results, although a phenomenological explanation might be found in the frame work of a model with two kinds of phonons which contribute differently to the thermal conductivity, thus given rise to a plateau or not. Here one must emphasize that the plateau seems to be a systematic property of amorphous dielectrics or semiconductors, and most probably is destroyed when the concentration of electrons is too high. Any fundamental theoretical model of this temperature-independent thermal conductivity around $10 \mathrm{~K}$ would probably have to include this feature.

Acknowledgments. - We wish to thank Prof. R. Maynard and Dr. J. C. Lasjaunias for helpful discussions of our results and critical reading of the manuscript.

\section{References}

[1] Löhneysen, H. V. and STeglich, F., Phys. Rev. Lett. 39 (1977) 1205.

[2] Löhneysen, H. V., Platte, W., Sander, W., Schink, H. J., Minnigerode, G. V. and Samwer, K., J. Physique Colloq. 41 (1980) C8-745.

[3] Graebner, J. E., Golding, B., Schutz, R. J., Hsu, F. S. L. and Chen, H. S., Phys. Rev. Lett. 39 (1977) 1480.

[4] Raychaudhuri, A. K. and Hasegawa, R., Phys. Rev. B 21 (1980) 479.

[5] Phillips, W. A., J. Low Temp. Phys. 7 (1972) 351.

[6] Anderson, P. W., Halperin, B. J. and Varma, C. M., Philos. Mag. 25 (1972) 1.

[7] Matey, J. R. and Anderson, A. C., Thermal conductivity 14, Ed. P. G. Klemens and T. K. Chu (Plenum Press, New York) 1976, p. 31, J. Non-Cryst. Solids 23 (1977) 129.

[8] Matey, J. R. and Anderson, A. C., Phys. Rev. B 16 (1977) 3406.

[9] Berry, B. S. and Pritchet, W. C., J. Appl. Phys. 44 (1973) 3127.

[10] Barmatz, M., Chen, H. S., Phys. Rev. B 9 (1974) 4073.

[11] Guessous, A., Matho, K., Mazuer, J., to be published.

[12] Chaussy, J., Guessous, A., Mazuer, J., Rev. Sci. Instrum. 52 (1981) 1721.

[13] Barnard, R. D., Thermoelectricity in Metals and Alloys (Taylor \& Francis Ltd., London) 1972.

[14] Blanc, J., Brochier, D., Lasjaunias, J. C., Maynard, R. and Ribeyron, A., Proceedings of 12th International Conference on Low Temperature Physics, Kyoto (1970).

[15] For a recent review of the problem, see

LöHneysen, H. V., Phys. Rep. 79 (1981) 161.

[16] Anderson, A. C., Thermal conductivity in amorphous solids, low temperature properties, Edited by W. A. Phillips (Springer Verlag, Berlin) 1981.

[17] Phillips, W. A., J. Non-Cryst. Solids 31 (1978) 267.

[18] Löhneysen, H. V., Herlach, D. M., Wassermann, E. F., SAmwer, K., Solid State Commun. 39 (1981) 591.

[19] Peyrard, J., Thèse Doctorat ès Sciences Physiques, Université de Grenoble (1980), unpublished.

[20] Below $10 \mathrm{~K}$ the decrease of $k_{\mathrm{ph}}$ with increasing Ce concentration might suggest strong phonon scattering by the felectrons of $\mathrm{Ce}$. But such a variation can also be attributed to $k_{\mathrm{ph}-\mathrm{i}}$ itself when considering the very large range of composition of the alloys.

[21] Kittel, Phys. Rev. 75 (1949) 972.

[22] Zaitlin, M. P. and Anderson, A. C., Phys. Rev. B 12 (1975) 4475.

[23] Dreyfus, B., Fernandes, N. C. and Maynard, R., Phys. Lett. 26A (1968) 647. 